\title{
El documental participativo: visibilidad y experiencia
}

\author{
Jacobo Sucari \\ Profesor universitario y realizador audiovisual \\ (Universitat de Barcelona)
}

\section{Referencia de este artículo}

Sucari, Jacobo (2020). El documental participativo: visibilidad y experiencia. adComunica. Revista Científica del Estrategias, Tendencias e Innovación en Comunicación, (19), 299-302. DOI: http://dx.doi.org/10.6035/2174-0992.2020.19.18.

Dar visibilidad, crear un mundo.

Desde los comienzos del cine, la reproducción mecánica de la imagen abrió un nuevo imaginario sobre la textura de lo real. Congelar el tiempo, acelerarlo, captar la luz y la materia de las cosas, sintetizar la lógica de los acontecimientos, constituyeron la base de un nuevo realismo. Un realismo heredero de la mirada renacentista del siglo XVI, con la ilusión de constituir el cuadro como si fuera una ventana y el marco como síntesis ilusoria de lo real mediante la técnica de la perspectiva. Dar visibilidad a las clases marginadas, fue la base del proyecto cinematográfico de Grierson en Inglaterra, tras participar en Estados Unidos de ese otro proyecto fotográfico en el participaron también Walker Evans y Dorothea Lange. Este momento sitúa el comienzo de una modernidad donde el retrato de la marginación y la pobreza configuran un escenario de la miseria en el capitalismo, que la cámara era capaz de mostrar de manera cruda y directa, yendo más allá de la capacidad de denuncia de cualquier texto escrito (Ibarz, 2008).

Dar visibilidad fue por lo tanto el punto de partida del documento fílmico que sacaba a la superficie lo que las élites poseedoras de los medios de producción querían mantener escondido, a ser: la miseria y la enfermedad, la lucha de clases 
en todas sus manifestaciones, las condiciones del trabajo y la devastación de la guerra: esconder, en síntesis, el dolor de lo real.

Desde un punto de vista constructivista, la realidad no es una dimensión fija que nos engloba, en forma de placenta, sino un sustrato que conformamos mediante acción y discurso. Esta percepción de una identidad compleja y en transformación de lo real se posicionó en forma política y estética en el medio cinematográfico propiciando una ruptura con un realismo óptico que consideraba la homología entre imagen y realidad.

El grupo Dziga Vertov a partir de sus Kinoks, expandiéndose en la dinámica de la revolución rusa, sostuvo que el cine documental es un medio capaz de construir otra realidad, o cuanto menos, una nueva dimensión de la realidad percibida a partir del mundo máquínico de la reproductibilidad. Desde este punto de vista el cine documental que sacaba a la luz procesos sociales y políticos se configuró como un campo de la expresión cinematográfica donde el proceso de trabajo se consideró tan importante como sus resultados. Un cine de experimentación procesual, que, desde una concepción diferenciada de la industria del cine, propiciaba otras percepciones constructivas de lo real.

La valoración catalizadora y revolucionaria del dispositivo técnico por parte de las vanguardias artísticas y políticas del siglo XX, supone una voluntad de crear una vinculación eminentemente física con la máquina, mediante una tecnología que crea, configura y revela estados de conciencia. El aparato técnico, siempre ha sido en este sentido, capaz de desvelar y crear realidad, de adoctrinar, de hacer propaganda, de crear luz, de despertar (o taponar) conciencia, y crear redes de pensamientos colectivos. Aquello que a partir de Deleuze y Guattari (1980) en nuestra contemporaneidad, entendemos como «agenciamientos colectivos» - la coerción del lenguaje normalizado, agenciamientos que conforman los enunciados de la realidad dominante.

Los grupos de video comunitario, que ejercieron un trabajo social mediante la herramienta audiovisual comenzaron su andar en los años 70 con la voluntad explícita de acercar el audiovisual a la ciudadanía y de empoderar a sus protagonistas. Las formas de este acercamiento no solo revestían un carácter de innovaciones en las maneras de las narrativas a través de la construcción colectiva del relato audiovisual, sino que además la accesibilidad a la tecnología del vídeo permitía acercar a diferentes comunidades a los procesos de producción audiovisual, creando una frontera híbrida entre el saber hacer del denominado equipo de producción, y el saber estar de los protagonistas del film.

Esta fórmula de renovación en la relación entre autor y protagonista se complementó con el perfil de un nuevo espectador, ya que los videos documentales producidos en esta fórmula colaborativa, más que dirigidos a un público de consumo televisivo, estaban dirigidos a la propia comunidad de origen, de manera que el 
producto audiovisual obtenido no acababa con la copia final del documental, como obra terminada para su difusión, sino que las proyecciones conjuntas y la realización de debates permitían continuar con el discurso de manera extra-fílmica.

En el Documental Social Participativo (DSP), lo cambios en las relaciones de poder entre los distintos roles, la necesidad de el establecimiento de dinámicas de grupo, el distanciamiento del equipo de producción de su propio saber técnico para dejar paso al diálogo e intercambio operativo con los protagonistas, y la nueva mirada requerida al espectador de este proceso constructivo, crean características que hacen necesario un marco singular de análisis de todo el fenómeno. Un análisis que no sólo sea capaz de nombrar las complejidades que un film desarrolla en cuanto obra acabada, sino que incluya las características del proceso y las estrategias del trabajo de campo llevado a cabo. Los procesos de transformación del documental participativo, mediante una nueva construcción de los procesos de representación, potencia un ejercicio de enunciación desde la base de los procesos culturales y no solo sobre las características de los hechos de cultura. Este modo participativo puede ser generador, en el sentido que potencie la acción extra-diegética de los protagonistas, es decir en que induce a la acción de los protagonistas, más allá del relato audiovisual, provocando una trama de enriquecimiento fuera y dentro del audiovisual.

\section{Referencias}

Ibarz, Llum (2008). Una larga y negra noche. Madrid: Éride.

Deleuze, Gilles; Guattari, Felix (1980). Política y psicoanálisis. México D. F: Terra Nova. 
